\title{
Molecular Mapping of the Stripe Rust Resistance Gene Yr69 on Wheat Chromosome 2AS
}

Liyuan Hou, College of Life Science, Shanxi University, Taiyuan 030006, Shanxi, China; Juqing Jia, College of Agronomy, Shanxi Agricultural University, Taigu 030801, Shanxi, China; Xiaojun Zhang and Xin Li, Institute of Crop Science, Shanxi Academy of Agricultural Sciences, Taiyuan 030031, Shanxi, China, and Shanxi Key Laboratory for Crop Genetics and Gene Improvement, Taiyuan 030031, Shanxi, China; Zujun Yang, School of Life Science and Technology, University of Electronic Science and Technology of China, Chengdu 610054, Sichuan, China; Jian Ma, Triticeae Research Institute, Sichuan Agricultural University, Chengdu 611130, Sichuan, China; and Huijuan Guo, Haixian Zhan, Linyi Qiao, and Zhijian Chang, Institute of Crop Science, Shanxi Academy of Agricultural Sciences, Taiyuan 030031, Shanxi, China, and Shanxi Key Laboratory for Crop Genetics and Gene Improvement, Taiyuan 030031, Shanxi, China

\begin{abstract}
Hou, L. Y., Jia, J. Q., Zhang, X. J., Li, X., Yang, Z. J., Ma, J., Guo, H. J., Zhan, H. X., Qiao, L. Y., and Chang, Z. J. 2016. Molecular mapping of the stripe rust resistance gene $\operatorname{Yr} 69$ on wheat chromosome 2AS. Plant Dis. 100:1717-1724.

Wheat is one of the major food crops in the world. Stripe rust, caused by Puccinia striiformis f. sp. tritici, is an economically important disease that affects wheat worldwide. The discovery of novel resistance genes and the deployment of effectively resistant cultivars are important for the ongoing control of wheat stripe rust and the maintenance of the agricultural productivity of wheat. CH7086, a new stripe rust-resistant wheat introgression line, was selected by crossing susceptible cultivars with the resistant Thinopyrum ponticum-derived partial amphiploid Xiaoyan 7430. The resistance of $\mathrm{CH} 7086$ is effective against all current Chinese P. striiformis f. sp. tritici races. $\mathrm{CH} 7086$ was crossed with the stripe rust-susceptible cultivars to develop $\mathrm{F}_{1}, \mathrm{~F}_{2}, \mathrm{~F}_{3}$, and $\mathrm{BC}_{1}$ populations for genetic analysis. Segregation in the $\mathrm{F}_{2}$ and $\mathrm{BC}_{1}$ populations and $\mathrm{F}_{2: 3}$

lines were tested for resistance against the $P$. striiformis $\mathrm{f}$. $\mathrm{sp}$. tritici race CYR32. This test showed that $\mathrm{CH} 7086$ carries a single dominant gene for stripe rust resistance, which was temporarily designated $\mathrm{YrCH} 86$. The closest of the eight simple sequence repeat (SSR) and expressed sequence tag-SSR markers flanking the locus were $X 2 A S 33$, which is $1.9 \mathrm{cM}$ distal, and Xmag 3807 , which is $3.1 \mathrm{cM}$ proximal. The resistance gene and its polymorphic markers were placed in deletion bin 2AS-0.78-1.00 using the 'Chinese Spring' nullisomic-tetrasomic, ditelosomic, and deletion lines. The tests of both allelism and resistance specificity suggested that the resistance gene found in $\mathrm{CH} 7086$ was not $\mathrm{Yr} 17$, which was the only current formally named $\mathrm{Yr}$ gene on chromosome 2AS. Thus, $\mathrm{YrCH} 86$ appeared to be a new locus and was permanently designated $\operatorname{Yr} 69$.
\end{abstract}

Food security currently depends on the production of wheat, corn, and rice, which are the three major cereals. Stripe (or yellow) rust of wheat, caused by the fungus Puccinia striiformis f. sp. tritici, is one of the major restraints to wheat production worldwide. It not only limits photosynthesis by reducing photosynthetic area but also secludes products for assimilation in spore production, which ultimately limits growth and yield, especially in moist and cool environments. The loss of crops to stripe rust is commonly in the range of 10 to $70 \%$, but under extreme epiphytotic conditions, this disease can increase losses to $100 \%$ (Chen 2005). In terms of crop area, China is the largest stripe rust-affected region in the world, with more than 20 million hectares of wheat vulnerable. In the years 1950, 1964, 1990, and 2002, severe epidemics caused significant yield losses estimated at $6.00,3.20,2.65$, and 1.40 million tons, respectively (Chen et al. 2009). The disease can be controlled economically through the use of foliar fungicides in high productivity areas. However, fungicides may add more cost, as well as potentially impacting the environment and human health. In addition, the use of fungicides continuously increases the selection pressure for potentially fungicide-tolerant strains of the pathogen. Accordingly, growing resistant cultivars is more effective for the control of stripe rust and can also have fewer detrimental environmental effects. However, the deployment of resistant cultivars depends upon

Corresponding author: Z. Chang; E-mail: wrczj@126.com;

Telephone: +86 35 17130805; Fax: +863517136763

L. Hou and J. Jia contributed equally to this work.

Accepted for publication 28 March 2016.

http://dx.doi.org/10.1094/PDIS-05-15-0555-RE

(C) 2016 The American Phytopathological Society the availability of resistance genes and detailed knowledge of their inheritance.

Two types of disease resistance to stripe rust are widely recognized, seedling resistance and adult plant resistance. Seedling resistance, also called all-stage resistance, is effective at the seedling stage but is also expressed during all growth stages, and adult plant resistance is expressed at the postseedling stage (Chen 2005). Currently, more than 60 permanently designated resistance genes to stripe rust ( $\mathrm{Yrl}$ to Yr67) have been cataloged in wheat (Cheng et al. 2014; http://shigen. nig.ac.jp/wheat/komugi/genes/macgene/supplement2013.pdf). Some of these genes have been widely used in wheat breeding worldwide (Chen 2005). However, genes for race-specific resistance are generally not durable in released resistant cultivars, due to the rapid selection through mutation or recombination and an increase of previously rare variants in the pathogen population. A good example of this occurring is $\operatorname{Yr} 9$. $\operatorname{Yr} 9$ is a rye-derived resistance gene that was introduced and broadly used in Chinese wheat breeding programs in the 1960s. It became ineffective due to the appearance and spread of the stripe rust race CYR29 in 1985, which led to yield losses of 2.65 million tons in 1990. A more recent destructive epidemic happened in 2002 and was caused by race CYR32. It affected varieties with the so-called Fan 6 source of resistance and led to production losses of 1.31 million tons (Wan et al. 2007). CYR32 and CYR33 were identified most often in China among the races detected from 1997 to 2009, and they played a major part in causing the widespread epidemics of wheat stripe rust in recent years (Chen et al. 2009; Zeng et al. 2014). These races have combined virulence for wheat containing the resistance genes $\mathrm{Yr} 3 b, \mathrm{Yr} 4 b, \mathrm{Yr} 9$, and $\mathrm{YrSu}$, one or more of which occurs in the cultivars covering $90 \%$ of the total winter wheat area in the entire country (Kang et al. 2010). Consequently, these races are major components of the pathogen population used by breeders when screening for stripe rust resistance (Wang et al. 2010). After the $\mathrm{Yr} 3 b, \mathrm{Yr} 4 b, \mathrm{Yr} 9$, and $\mathrm{YrSu}$ genes became 
ineffective against the predominant races of stripe rust, lines and cultivars with $\operatorname{Yr} 24$ (= Yr26) were widely grown in Sichuan and Gansu provinces (Li et al. 2006). During the 2008-2009 crop season, a new race, CH42 (or v26), was detected in Sichuan on the previously leading resistant wheat $\mathrm{cv}$. Chuanmai 42 containing the Yr24 gene (Liu et al. 2010). This race is also virulent to wheat lines with $\operatorname{Yr} 10$, which is effective against all previously identified Chinese P. striiformis f. sp. tritici races (Zeng et al. 2014). Therefore, an effective strategy to counter the detrimental effects of the evolution of new rust pathotypes is to search for new rust resistance genes and, subsequently, strategically deploy these new genes in commercial cultivars.

Molecular markers are useful in genetic mapping in wheat. Molecular markers are based on polymorphisms in DNA sequences and are independent of the environmental and developmental factors. Therefore, they facilitate the selection of the genes controlling a trait like disease resistance. Simple sequence repeats (SSR), or microsatellites, are one of the favored genetic markers due to their high level of polymorphism, genomic abundance, and codominance. Closely linked microsatellite markers have already been reported for many stripe rust resistance genes, including Yr5, Yr15 (Murphy et al. 2009), Yr10 (Singh et al. 2009), Yr17 (Helguera et al. 2003; Jia et al. 2011), Yr24/Yr26 (Wang et al. 2008), Yr50 (Liu et al. 2013), Yr64, and Yr65 (Cheng et al. 2014). Molecular markers closely linked to such genes have been useful in map-based cloning (Fu et al. 2009) and have facilitated the utilization and incorporation of multiple genes into breeding programs (Murphy et al. 2009).

In our previous screen of the wheat germplasm for resistance to stripe rust in the field nurseries at Chengdu, Sichuan province and under greenhouse conditions at Taiyuan, Shanxi province from 2005 to 2012 , we identified a number of common wheat genotypes with effective resistance against the common Chinese races, including CYR32, CYR33, and CH42 (Zhijian Chang unpublished data). The objectives of the present study were to characterize stripe rust resistance in the wheat germplasm line $\mathrm{CH} 7086$ and to identify molecular markers closely linked to it.

\section{Materials and Methods}

Plant materials and populations. The $\mathrm{CH} 7086$ line analyzed in this study is a homogeneous $\mathrm{BC}_{2} \mathrm{~F}_{7}$-derived wheat line that was produced by crossing the hexaploid wheat (Triticum aestivum L.) cv. Zhong (Z) 8701 accession, as the female parent, with the Xiaoyan (XY) 7430 accession, as the donor of stripe rust resistance. The hybrid was backcrossed twice to another wheat accession, cv. Jimai (JM) 26, and the resulting resistant plants from the $\mathrm{BC}_{2} \mathrm{~F}_{2}$ population were allowed to self-fertilize for five generations. The XY 7430 accession is a Thinopyrum ponticum-derived partial amphiploid with the pedigree of Misuizao (MSZ)/R431 (a Thinopyrum ponticum accession from the former Soviet Union) and Xiangyang (XY) 4 (Li et al. 1985).

Other plant materials including the Thinopyrum ponticum accession R431, XY 7430, and all the wheat parents involved in breeding $\mathrm{XY} 7430$ and $\mathrm{CH} 7086$ (Table 1) were used in testing the reactions to the $P$. striiformis f. sp. tritici races to see if the resistance was derived from this wild species. Also included were the wheat genotype 'Chinese Spring' (CS) and various CS nullisomic-tetrasomic (NT) and ditelosomic (Dt) stocks and deletion lines obtained from B. Friebe, Wheat Genetic and Genomic Resources Center, Kansas State University (Manhattan, KS, U.S.A.).

CH7086 confers a high level of resistance to all the existing Chinese $P$. striiformis f. sp. tritici races, whereas Taichung (TC) 29 and Mianyang (MY) 11 are susceptible to most stripe rust races. To study the inheritance of the stripe rust resistance, $\mathrm{CH} 7086$ was crossed to the susceptible cultivars TC 29 and MY 11 to generate segregating populations. $\mathrm{F}_{2}, \mathrm{~F}_{3}$, and $\mathrm{BC}_{1}$ populations were tested for stripe rust response. $\mathrm{A}_{2}$ population and the derived $\mathrm{F}_{3}$ families from the TC $29 \times$ CH7086 cross were further used for molecular marker screening and genetic mapping. The mapping population was comprised of $205 \mathrm{~F}_{2}$ plants and 198 derived $\mathrm{F}_{3}$ families. The difference between the $F_{2}$ plants and the $F_{3}$ families is due to the loss of seven susceptible $\mathrm{F}_{2}$ plants.

Table 1. Seedling infection types on selected donor lines, parents and controls using the nine Chinese races of Puccinia striiformis f. sp. tritici

\begin{tabular}{|c|c|c|c|c|c|c|c|c|c|c|c|c|}
\hline \multirow[b]{2}{*}{ Race } & \multicolumn{2}{|c|}{ Virulent to } & \multicolumn{10}{|c|}{ Infection type $^{\text {b }}$} \\
\hline & Differential line $^{\mathrm{a}}$ & Known $Y r$ gene & CH7086 & TC 29 & MY 11 & MX 169 & $\mathbf{R 4 3 1}$ & XY7430 & MSZ & XY 4 & Z8701 & $\overline{J M ~ 26}$ \\
\hline CYR23 & $1,2,3,4,6,7,8,9,11$ & $1,3,6$ & 0 & 1 & 0 & 4 & 0 & 0 & 3 & 0 & 1 & 4 \\
\hline CYR29 & $\begin{array}{l}1,2,3,4,5,6,7,8,9,11, \\
12,16,20,21,24\end{array}$ & $\begin{array}{l}1,2,3,3 a, 4 a, 6,9,13 \\
17,25, \operatorname{Vir}_{1-2}, A\end{array}$ & 0 & 4 & 3 & 4 & 0 & 0 & 4 & 4 & 4 & 3 \\
\hline CYR31 & $\begin{array}{c}1,2,3,4,5,6,7,8,9 \\
11,12,14,16,17\end{array}$ & $\begin{array}{l}1,3,4 b, 6,9, H 46, S u \\
\operatorname{Vir}_{1-2}, A\end{array}$ & 0 & 4 & 4 & 4 & 0 & 0,0 & 4 & 3 & 4 & 3 \\
\hline CYR32 & $\begin{array}{l}1,2,3,4,5,6,7,8,9,10 \\
11,12,13,14,16,17 \\
20,21,24\end{array}$ & $\begin{array}{l}1,2,3,3 a, 4 a, 4 b, 6,9,13 \\
17,25, H 46, S u, \operatorname{Vir}_{1-2} \\
A, K y_{1-2}, J u_{1-4}\end{array}$ & 0 & 4 & 4 & 4 & 0 & 0 & 4 & 4 & 4 & 4 \\
\hline CYR33 & $\begin{array}{c}1,2,3,4,5,6,7,8,9,10,11 \\
12,13,14,16,24\end{array}$ & $\begin{array}{l}1,3,6,9,17, S u, \operatorname{Vir}_{1-2} \\
\quad A, K y_{1-2}, J u_{1-4}\end{array}$ & 0 & 4 & 4 & 4 & 0 & 0,0 & 4 & 4 & 3 & 4 \\
\hline Su11-4 & $\begin{array}{l}2,3,4,6,7,8,9,10 \\
13,14,16\end{array}$ & $1,3,9, S u, A, K y_{1-2}, J u_{1-4}$ & 0 & 4 & 4 & 3 & 0 & 0 & 0 & 3 & 4 & 0 \\
\hline Su11-5 & $\begin{array}{l}1,2,3,4,5,6,7,8,9 \\
11,14,16\end{array}$ & $1,3,6,9, S u, \operatorname{Vir}_{1-2}, A$ & 0 & 3 & 4 & 4 & 0 & 0 & 1 & 4 & 3 & 3 \\
\hline Su11-7 & $1,2,3,6,7,8,9,11,14$ & $1,3,6,9, S u, A$ & 0 & 0 & 3 & 4 & 0 & 0 & 4 & 1 & 0 & 4 \\
\hline $\mathrm{CH} 42$ & $19,22,25,26$ & $10,24 / 26$ & 0 & 0 & 3 & 4 & 0 & 0 & 4 & 4 & 4 & 3 \\
\hline
\end{tabular}

${ }^{a}$ Differential lines: $1=$ Trigo Eureka $(Y r 6), 2=$ Fulhard, $3=$ Lutescens 128, $4=$ Mentana, $5=$ Virgilio $(Y r V i r 1, Y r V i r 2), 6=$ Abbondanza, $7=$ Early Premium, $8=$ Funo $(Y r A), 9=$ Danish $1(Y r 3), 10=$ Jubilejina $2(Y r J u 1, Y r J u 2, Y r J u 3, Y r J u 4), 11=$ Fengchan $3(Y r 1), 12=$ Lovrin $13(Y r 9), 13=\operatorname{Kangyin} 655(Y r 1, Y r K y 1$, YrKy2), 14 = Suwon 11 (YrSu), 15 = Zhong 4, $16=$ Lovrin $10(Y r 9), 17=$ Hybrid $46(Y r 4 b, Y r H 46), 18=$ Triticum spelta album $(Y r 5), 19=$ Guinong 22, $20=$ Maris Huntsman $(Y r 2, Y r 3 a, Y r 4 a, Y r 13), 21=$ Heines VII $(Y r 2, Y r 25), 22=$ AvS Yr10NIL $(Y r 10), 23=$ AvS Yr15NIL $(Y r 15), 24=$ AvS Yr17NIL $(Y r 17), 25=$ AvS Yr24NIL (Yr24), and 26 = AvS Yr26NIL (Yr26). Information on the virulence formula was based on Li et al. (2006), Chen et al. (2009), and Zeng et al. (2014).

b Seedling infection types are as described by Li and Zeng (2002): $0=$ no visible symptoms; 0 ; = hypersensitive flecks or necrotic areas without sporulation; $1=$ necrotic and chlorotic areas with restricted sporulation; $2=$ moderate sporulation with necrosis and chlorosis; $3=$ sporulation with chlorosis; $4=$ abundant sporulation without chlorosis. Scores of 0 to 2 were considered resistant and 3 and 4 susceptible. XY (Xiaoyan) 7430, the resistance donor of CH7086 is a partial amphiploid with 56 chromosomes and a genomic formula consisting of the wheat complement plus 14 chromosomes from the $\mathrm{J}$ and $\mathrm{J}^{\mathrm{s}}$ genomic sets of Thinopyrum ponticum. R431: Thinopyrum ponticum accession of the wild parent of XY7430 with 70 chromosomes and a genomic formula of JJJJ' Js. MSZ (Misuizao) and XY (Xiangyao) 4: the wheat parents of XY 7430; Z (Zhong) 8701 and JM (Jimai) 26: the wheat parents of CH7086. 
Pathogen materials and stripe rust response phenotypes. Nine Chinese P. striiformis f. sp. tritici races (CYR23, CYR29, CYR31, CYR32, CYR33, SY11-4, SY11-5, SY11-7, and CH42) (Table 1) with various virulence gene combinations (Chen et al. 2009; $\mathrm{Li}$ et al. 2006; Zeng et al. 2014) were selected to test seedlings of the CH7086, TC 29, and MY 11 plants based on methods described by Li and Zeng (2002). CH42 is a new $\mathrm{Yr} 24 / \mathrm{Yr} 26$-virulent race that is different from other currently known races in China (Liu et al. 2010). The remaining races cover all of the Chinese race groups and represent the most widely virulent and/or predominant races collected from 2003 to 2007 in the wheat-growing areas of 15 provinces (Chen et al. 2009).

Seedlings of each accession were grown in $70 \times 45 \times 18$-cm flat plastic trays. The highly susceptible cv. Mingxian (MX) 169 was used as a control. Inoculations were performed when the first leaves were fully expanded. Inoculated seedlings were kept in a dew chamber at $17^{\circ} \mathrm{C}$ for approximately $24 \mathrm{~h}$ and, then, were moved to an environmentally controlled greenhouse with a daily cycle of $16 \mathrm{~h}$ of light at $18^{\circ} \mathrm{C}$ and $8 \mathrm{~h}$ of dark at $17^{\circ} \mathrm{C}$. Reactions were scored on a 0 to 4 scale (Li and Zeng 2002) 18 to 21 days postinoculation, when the susceptible controls were heavily infected (Table 1).

Race CYR32, which is avirulent to CH7086 but virulent to TC 29 and MY 11, was used to test the $\mathrm{F}_{1}, \mathrm{~F}_{2}$, and $\mathrm{BC}_{1}$ populations derived from the TC $29 \times \mathrm{CH} 7086$ and $\mathrm{CH} 7086 \times$ MY 11 crosses (Table 2). Seeds from the parents, $\mathrm{F}_{1}, \mathrm{~F}_{2}, \mathrm{~F}_{3}$, and $\mathrm{BC}_{1}$ populations were planted in the field nursery in Chengdu. Eighteen seeds for each parent and $\mathrm{F}_{1}, 180$ to 220 seeds of the $\mathrm{F}_{2}, 120$ seeds of the $\mathrm{BC}_{1}$, and 15 to 20 seeds for each $\mathrm{F}_{2}$-derived $\mathrm{F}_{3}$ family were planted in a randomized design with 15 to 20 plants in a $1.6-\mathrm{m}$ row, $25 \mathrm{~cm}$ apart. Susceptible spreaders, we used the cvs. MX 169 or Huixianhong, were planted in every tenth row for each population. The predominant $P$. striiformis f. sp. tritici race CYR32 was used for adult plant testing and the spreaders were artificially inoculated two to three times at the seedling stage. Epidemics were initiated by spraying aqueous suspensions of urediniospores of CYR32 with $0.03 \%$ Tween 20 onto the spreader rows at tillering. Adult plant reactions were scored at the soft dough stage using the 0 to 4 scale as described by Li and Zeng (2002). The $\mathrm{F}_{2: 3}$ plants were tested with the same $P$. striiformis f. sp. tritici race to determine the genotypes of the $\mathrm{F}_{2}$ plants from the TC $29 \times \mathrm{CH} 7086$ and $\mathrm{CH} 7086 \times$ MY 11 crosses.

Additionally, the $\mathrm{F}_{2}$ population of the AvS Yr17NIL $\times \mathrm{CH} 7086$ cross was evaluated in the greenhouse, using race CYR23 to test for allelism of the stripe rust resistance genes in CH7086 and AvS Yr17NIL. Stripe rust inoculation, incubation of the infected plants, and rust scoring also followed Li and Zeng (2002).

Bulk segregant analysis. The parents and $198 \mathrm{~F}_{2: 3}$ families were subjected to SSR analysis. Total DNA was extracted from the leaves following the protocol by Stein et al. (2001). Resistant (Br) and susceptible $(B s)$ bulks were made from equal amounts of DNA from 10 resistant and 10 susceptible $\mathrm{F}_{2}$ plants, respectively. DNA bulks of 10 homozygous resistant (HR) and 10 homozygous susceptible (HS) $\mathrm{F}_{2: 3}$ lines were similarly prepared for bulk segregant analysis (BSA). Markers polymorphic between the resistant and susceptible parents and bulks were used to genotype the entire $\mathrm{F}_{2}$ and $\mathrm{F}_{2: 3}$ populations.

Molecular marker analysis. For the initial survey of polymorphic markers, one primer pair from each of the Xgwm, Xwmc, Xbarc, Xcfd, $X c f a$, and $X g d m$ SSR marker series was selected approximately every $10 \mathrm{cM}$ along the chromosomes, according to the reported consensus map (Somers et al. 2004), and was used in BSA. Additional markers from the above series and the Xgpw chromosome 2A markers, which showed polymorphisms between the resistant and susceptible bulks, were used in genotyping individual plants.

PCR for each SSR marker was performed using a PTC200 Peltier thermal cycler (Bio-Rad Inc., Hercules, CA) in a total volume of $20 \mu \mathrm{l}$ containing $2 \mu \mathrm{l}$ of $10 \times$ buffer $(10 \mathrm{mM}$ Tris-HCl, $\mathrm{pH} 8.3$, $50 \mathrm{mM} \mathrm{KCl}, 1.5 \mathrm{mM} \mathrm{MgCl} 2$ ), $0.2 \mathrm{mM}$ of each dNTP, 1 unit Taq DNA polymerase, $0.25 \mu \mathrm{M}$ of each primer, and 80 to $100 \mathrm{ng}$ of total DNA. Each PCR reaction was performed at $94^{\circ} \mathrm{C}$ for $5 \mathrm{~min}$, followed by 35 cycles of $94^{\circ} \mathrm{C}$ for $45 \mathrm{~s}, 50,55$, or $60^{\circ} \mathrm{C}$ (based on primer annealing temperatures) for $45 \mathrm{~s}, 72^{\circ} \mathrm{C}$ for $1 \mathrm{~min}$, and a final extension at $72^{\circ} \mathrm{C}$ for $10 \mathrm{~min}$, before cooling to $4^{\circ} \mathrm{C}$. After amplification, $12 \mu \mathrm{l}$ of loading buffer $(0.4 \mathrm{~g}$ of sucrose per milliliter, $1 \mathrm{mg}$ of bromophenol blue per milliliter, and $1 \mathrm{mg}$ of xylene cyanol per milliliter) were added to the PCR products; 4 to $6 \mu$ l of each sample were loaded on an $8 \%$ nondenaturing polyacrylamide gels (Acr:Bis $=$ 29:1) and were separated at $150 \mathrm{~V}$ for approximately $2 \mathrm{~h}$, then, were visualized by silver staining.

The availability of the wheat chromosome shotgun survey sequences makes it possible to develop molecular markers. Wheat expressed sequence tags (ESTs) located in bin 2AS-0.78-1.00 were retrieved from GrainGenes 2.0 (http://wheat.pw.usda.gov/). These ESTs were blasted against 2AS survey sequences (International Wheat Genome Sequencing Consortium 2014) using BLASTN with an E-value of 0.00001. The contig sequences with the best hits to the ESTs in the blast results were further retrieved and were uploaded onto SSR Primer II (Jewell et al. 2006) to search for SSR markers. The PCR products amplified using the developed SSR markers were separated on $8 \%$ nondenaturing polyacrylamide gels.

Chromosome bin assignment and linkage analysis. Chromosomal locations and physical bin mapping of linked microsatellite markers were confirmed using CS nullisomic 2A tetrasomic 2B (N2AT2B), N2BT2D, N2DT2A, and ditelosomic 2AS (Dt2AS) stocks, and the CS chromosome 2AS deletion lines. Linkages between the DNA markers and the resistance gene were established

Table 2. Adult plant segregation of stripe rust responses in the $\mathrm{F}_{2}$ and $\mathrm{BC}_{1}$ populations and the $\mathrm{F}_{3}$ lines when inoculated with the Puccinia striiformis $\mathrm{f}$. sp. tritici race $\mathrm{CYR} 32^{\mathrm{a}}$

\begin{tabular}{|c|c|c|c|c|c|c|c|c|c|c|c|c|c|c|}
\hline \multirow[b]{4}{*}{ IT } & & & & \multicolumn{5}{|c|}{$\mathbf{P}_{2} / \mathbf{P}_{1}$} & \multicolumn{5}{|c|}{$\mathbf{P}_{1} / \mathbf{P}_{3}$} & \multirow{4}{*}{$\frac{\frac{P_{1} / P_{3} / / P_{3}}{\text { No. of plants }}}{B_{1}}$} \\
\hline & & & & & & & No. of & & & & & No. of & & \\
\hline & \multicolumn{3}{|c|}{ Parent } & \multicolumn{2}{|c|}{ No. of plants } & \multicolumn{3}{|c|}{$F_{2: 3}$} & \multicolumn{2}{|c|}{ No. of plants } & \multicolumn{3}{|c|}{$\mathbf{F}_{2: 3}$} & \\
\hline & $\overline{P_{1}}$ & $\mathbf{P}_{2}$ & $\overline{\mathbf{P}_{3}}$ & $\overline{F_{1}}$ & $\overline{F_{2}}$ & HR & Seg & HS & $\mathbf{F}_{1}$ & $\mathbf{F}_{2}$ & HR & Seg & HS & \\
\hline 0 & 13 & & & 11 & 17 & 14 & 3 & 0 & 10 & 26 & 21 & 5 & 0 & 17 \\
\hline 0 & 2 & & & 3 & 79 & 33 & 46 & 0 & 4 & 51 & 13 & 38 & 0 & 28 \\
\hline 1 & & & & & 40 & 3 & 37 & 0 & & 33 & 9 & 24 & 0 & 9 \\
\hline 2 & & & & & 16 & 0 & 16 & 0 & & 14 & 3 & 10 & 1 & 4 \\
\hline 3 & & & & & 10 & 0 & 2 & 8 & & 11 & 0 & 3 & $5^{\mathrm{b}}$ & 8 \\
\hline 4 & & 13 & 14 & & 43 & 0 & 0 & $36^{\mathrm{c}}$ & & 32 & 0 & 0 & $24^{\mathrm{d}}$ & 39 \\
\hline \multirow[t]{2}{*}{ Total } & 15 & 13 & 14 & 14 & 205 & 50 & 104 & $44+7$ & 14 & 167 & 46 & 80 & $30+11$ & 105 \\
\hline & & & & \multicolumn{2}{|c|}{$\begin{aligned} \chi_{(3: 1)}^{2} & =0.08 \\
P & =0.78\end{aligned}$} & \multicolumn{3}{|c|}{$\begin{aligned} \chi_{(1: 2: 1)}^{2} & =0.87 \\
P & =0.65\end{aligned}$} & \multicolumn{2}{|c|}{$\begin{aligned} \chi_{(3: 1)}^{2} & =0.05 \\
P & =0.82\end{aligned}$} & \multicolumn{3}{|c|}{$\begin{aligned} \chi_{(1: 2: 1)}^{2} & =3.38 \\
P & =0.18\end{aligned}$} & $\chi_{(1: 1)}^{2}=1.15$ \\
\hline
\end{tabular}

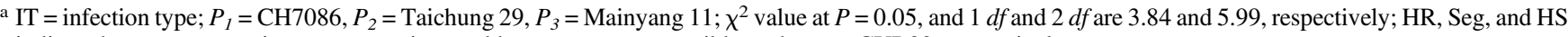
indicate homozygous resistant, segregating, and homozygous susceptible to the race CYR32, respectively.

b Three plants dead in the field. They were assumed to be HS.

${ }^{c}$ Seven plants dead in the field. They were assumed to be HS.

${ }^{\mathrm{d}}$ Eight plants dead in the field. They were assumed to be HS. 
with JoinMap version 4.0 software (van Ooijen 2006) with a logarithm of odds threshold of 3.0. Map distances were determined using the Kosambi mapping function.

\section{Results}

Phenotypic characterization and inheritance of stripe rust resistance. Seedling infection type (IT) data for $\mathrm{CH7086,} \mathrm{TC}$ 29, and MY 11 tested using the nine Chinese $P$. striiformis f. sp. tritici races are shown in Table 1. CH7086 was resistant (IT 0-0;) to all races at the seedling stage, whereas MY 11 was susceptible to all races except CYR23, and TC 29 was resistant to races CYR23, SY11-7, and $\mathrm{CH} 42$. These results demonstrated that $\mathrm{CH} 7086$ conferred a high level of resistance to all the Chinese $P$. striiformis $\mathrm{f}$. sp. tritici races tested.

The adult plant IT data for the parents, $\mathrm{F}_{1}$ plants, $\mathrm{F}_{2}$, and $\mathrm{BC}_{1}$ populations are summarized in Table 2. When inoculated with race CYR32 at the adult plant stage, CH7086 was highly resistant (IT 0), whereas TC 29 and MY 11 were highly susceptible (IT 4). F $_{1}$ plants from both crosses were highly resistant and showed ITs (IT 0-0;) similar to the resistant parent $\mathrm{CH} 7086$, indicating that the resistance was completely dominant. Some plants in the $\mathrm{F}_{2}$ and $\mathrm{BC}_{1}$ populations (Table 2) had intermediate responses. When the numbers of $F_{2}$ plants with IT 0 to 2 and IT 3 to 4 were pooled as separate resistant and susceptible groups, respectively, the ratios conformed to those expected for segregation at a single locus. When tested with the same race, the $\mathrm{F}_{3}$ lines from the TC $29 \times \mathrm{CH} 7086$ and $\mathrm{CH} 7086 \times \mathrm{MY} 11$ crosses segregated 1:2:1 HR:segregating (Seg):HS, confirming the segregation of a single gene (Table 2 ). In addition, the pooled numbers of resistant and susceptible plants in segregating $\mathrm{F}_{3}$ lines from the Taichung $29 \times \mathrm{CH} 7086$ cross were 1,327 resistant and 424 susceptible $\left(\chi_{(3: 1)}^{2}=0.58, P_{1 \mathrm{df}}=0.45>0.25\right)$. These results suggested that a stripe rust resistance gene, provisionally designated $\mathrm{YrCH} 86$, was present in $\mathrm{CH} 7086$.

Almost all of the 17 plants scored IT 0 in the $\mathrm{F}_{2}$ population from the TC $29 \times \mathrm{CH} 7086$ cross were HR in tests on the $\mathrm{F}_{3}$ lines. Of the 56 plants scored IT 1 or 2,53 produced $\mathrm{Seg}_{\mathrm{F}}$ lines, and three were HR in the $\mathrm{CH} 7086 \times$ MY 11 cross, 21 of 26 plants that were scored IT 0 were $\mathrm{HR}$ and five segregated as $\mathrm{F}_{3}$ lines. Thirteen of 51 plants that were scored IT 0 were HR and 38 segregated as $\mathrm{F}_{3}$ lines, whereas among the 47 that scored IT 1 or 2, 34 segregated and 12 were HR. In both populations, the $\mathrm{F}_{3}$ distributions of $\mathrm{HR}$, Seg, and HS showed a good fit to a 1:2:1 ratio, indicating a single dominant gene could confer the resistance in $\mathrm{CH} 7086$. Again, very low proportions of the plants from the two crosses (two plants from TC $29 \times \mathrm{CH} 7086$ and three plants from $\mathrm{CH} 7086 \times \mathrm{MY} 11)$ that were scored IT 3 proved to be heterozygous rather than HS upon $\mathrm{F}_{3}$ progeny testing (Table 2).
Identification and mapping of the markers linked to $\mathrm{YrCH} 86$. To identify markers linked to $\mathrm{YrCH}$ 86, primer pairs for the SSR markers distributed on all of the chromosomes were used in BSA, using the $198 \mathrm{~F}_{2}$ plants from the TC $29 \times \mathrm{CH} 7086$ cross. The rust response genotypes were inferred from segregation of the $\mathrm{F}_{3}$ families. Of the 608 GWM, WMC, BARC, CFD, CFA, and GDM microsatellite primers chosen for initial screening, 211 (34.7\%) were polymorphic between the parental lines. Only markers Xwmc382 and Xgwm636, which were previously located on chromosome arms 2AS and 2BS, respectively (Somers et al. 2004), were polymorphic between the contrasting parental and bulk populations. The fragments amplified by WMC382 were approximately 160 and $148 \mathrm{bp}$, and those amplified by GWM636 were approximately 95 and $110 \mathrm{bp}$ in the resistant and susceptible parents, respectively, indicating that these markers are associated with $\mathrm{YrCH} 86$. Therefore, an additional 76 markers on chromosome $2 \mathrm{~A}$ were examined, and four polymorphic SSR markers, Xgpw7101, Xgwm210, Xwmc25, and Xbarc124, and one sequence-tagged site (STS) marker, Xmag3807, were associated with resistance in both the bulk segregant pools and the parents (Fig. 3). These markers were used for genotyping in all 198 surviving plants of the $F_{2}$ population. Linkage analyses confirmed the genetic associations of the six SSR and one STS markers with stripe rust resistance. The $F_{2}$ population segregated either $3: 1$ or $1: 2: 1$ for all seven markers (Table 3 ). Analyses with JoinMap also showed linkage between the markers and $\mathrm{YrCH} 86$. $X g w m 636, X g p w 7101, X w m c 382$, and Xgwm210 were proximal to the resistance gene and Xwmc25, Xmag3807, and Xbarc124 were distal. A linkage map of gene $\mathrm{YrCH} 86$ and the closely linked markers with a total map length of $28.2 \mathrm{cM}$ was constructed (Fig. 2).

$\mathrm{YrCH} 86$ was bordered distally by Xgwm636 and proximally by Xbarc124 (Fig. 2). Both of these markers are located in deletion bin 2AS5 FL 0.78-1.00 (http://wheat.pw.usda.gov/ggpages/SSRclub/ GeneticPhysical/). A total of 104 SSR markers that were designed based on the sequences of the wheat ESTs assigned to this chromosome region were further tested for the discovery of polymorphic markers. Among them, only the EST-SSR marker X2AS33 (F: atttgtttacgccgagca, R: atccagcattacattacatca) was associated with $\mathrm{YrCH} 86$ (Fig. 1A). Based on the linkage analysis, $\mathrm{YrCH} 86$ was placed on chromosome 2AS in bin 2AS5-0.78-1.00 and was flanked by markers X2AS33 and Xmag3807 at genetic distances of 1.9 and $3.1 \mathrm{cM}$, respectively (Fig. 2).

Chromosome regional assignment and the possible source of $\mathrm{YrCH86.} \mathrm{Based} \mathrm{on} \mathrm{the} \mathrm{reported} \mathrm{chromosomal} \mathrm{locations} \mathrm{of} \mathrm{the}$ linked markers (Eriksen et al. 2004; Marone et al. 2012; Somers et al. 2004), $\mathrm{YrCH} 86$ was putatively assigned to the short arm of chromosome 2A (2AS). However, microsatellite markers are not

Table 3. $\mathrm{F}_{2}$ genotypes of the Taichung $29 \times \mathrm{CH} 7086$ cross inferred from the stripe rust reactions of $\mathrm{F}_{3}$ families and the corresponding alleles at the eight marker loci $^{\mathrm{a}}$

\begin{tabular}{|c|c|c|c|c|c|c|c|c|c|c|c|c|c|}
\hline \multirow[b]{2}{*}{ Genotype } & \multirow[b]{2}{*}{ Total } & \multicolumn{3}{|c|}{ Xbarc124 } & \multicolumn{2}{|c|}{ Xwmc25 } & \multicolumn{4}{|c|}{ Xwmc382 } & & \multicolumn{2}{|c|}{ Xmag3807 } \\
\hline & & & $A-\mathbf{a}$ & & A- & aa & $\mathbf{A A}$ & & & aa & & A- & aa \\
\hline$Y r Y r$ & 40 & & 30 & & 34 & 6 & 33 & & & 1 & & 35 & 5 \\
\hline Yryr & 82 & & 6 & & 5 & 77 & 5 & & & 9 & & 5 & 77 \\
\hline yryr & 36 & & 1 & & 0 & 36 & 0 & & & 30 & & 1 & 35 \\
\hline Total & 158 & & 37 & & 39 & 119 & 38 & & & 40 & & 41 & 117 \\
\hline$\chi^{2}(3: 1 \text { or } 1: 2: 1)^{b}$ & 0.430 & \multicolumn{3}{|c|}{0.211} & \multicolumn{2}{|c|}{0.008} & \multicolumn{5}{|c|}{0.076} & \multicolumn{2}{|c|}{0.076} \\
\hline \multirow[t]{2}{*}{$P$} & 0.806 & \multicolumn{3}{|c|}{0.646} & \multicolumn{2}{|c|}{0.927} & \multicolumn{4}{|c|}{0.962} & \multicolumn{3}{|c|}{0.783} \\
\hline & & \multicolumn{3}{|c|}{ Xgwm210 } & \multicolumn{2}{|c|}{ Xgpw7101 } & \multicolumn{3}{|c|}{ Xgwm636 } & & \multicolumn{3}{|c|}{$X 2 A S 33$} \\
\hline Genotype & Total & $\mathbf{A A}$ & & $\overline{\mathbf{a a}}$ & A- & aa & $\mathbf{A A}$ & Aa & $\overline{\mathbf{a a}}$ & & $\mathbf{A A}$ & Aa & $\mathbf{a a}$ \\
\hline$\overline{Y r Y r}$ & 40 & 34 & & 0 & 35 & 5 & 32 & 7 & 1 & & 36 & 4 & $\overline{0}$ \\
\hline Yryr & 82 & 4 & & 8 & 8 & 74 & 5 & 67 & 10 & & 2 & 77 & 3 \\
\hline yryr & 36 & 0 & & 30 & 0 & 36 & 0 & 4 & 32 & & 0 & 2 & 34 \\
\hline Total & 158 & 38 & & 38 & 43 & 115 & 37 & 78 & 43 & & 38 & 83 & 37 \\
\hline$\chi^{2}(3: 1 \text { or } 1: 2: 1)^{b}$ & 0.430 & & & & & & & 0.481 & & & & 0.418 & \\
\hline$P$ & 0.806 & & & & & & & 0.786 & & & & 0.812 & \\
\hline
\end{tabular}

a A- = AA or Aa; aa = homozygous for the Taichung 29 allele; $\mathrm{AA}=$ homozygous for the CH7086 allele, Aa = heterozygous.

b Table values of $\chi^{2}$ for significance at $P=0.05$, and $1 d f$ and $2 d f$ are 3.84 and 5.99, respectively. 
always chromosome-specific (Plaschke et al. 1996). Among the SSR markers linked with $\mathrm{YrCH} 86$, only Xbarc124 and Xgwm636 had previously been mapped solely to chromosome arm $2 \mathrm{AS}$. The remaining markers were reported to occur at more than one location in the genome. For example, Xgwm 210 was assigned to all three chromosomes in the homeologous group $2 \mathrm{~S}, X w m c 382$ to $2 \mathrm{AS}$ and $2 \mathrm{BS}$, and Xgpw7101 to 2AS and 2DS (Somers et al. 2004; Xue et al. 2008). Although most of the markers detect multiple loci, 2AS is a common location for all of them. The locations of the linked marker loci were further verified using CS nullisomic-tetrasomic and ditelosomic lines. Microsatellite primer pairs GWM636, GPW7101, WMC382, GWM210, WMC25, and BARC124 amplified products of the expected size in the CS, CS N2BT2D and N2DT2A, and CS Dt2AS lines, but no PCR products were amplified in the N2AT2B, N2AT2D, and Dt2AL lines (Fig. 3). These results further confirmed the positioning of the linked microsatellite markers to chromosome 2AS.
The microsatellite markers Xgwm636 and Xbarc124 linked with the resistance gene were $25.2 \mathrm{cM}$ apart on chromosome arm 2AS (Fig. 2). Because these markers are located in deletion bin 2AS5-0.78-1.00 (Sourdille et al. 2004), we bin-mapped all our markers using the CS deletion lines. All of the markers linked to the resistance gene, including Xgwm636, Xgpw7101, Xwmc382, Xgwm210, Xwmc25, and Xbarc124, and the EST-SSR markers Xmag3807 and X2AS33 were located in the 2AS5 deletion bin. $\mathrm{YrCH} 86$ was placed in the interval flanked by $X 2 A S 33$ and Xmag3807, and the physical location of $\mathrm{YrCH} 86$ was positioned in the 2AS5 deletion bin. The physical and genetic maps of $\mathrm{YrCH} 86$ and the four codominant and four dominant markers are shown in Figure 2.

In the genomic in situ hybridization (GISH) experiment (data not shown) and our earlier work (Zhan et al. 2014), no signal could be detected in $\mathrm{CH} 7086$ when using the total genomic DNA of

$F_{2}$ Plants

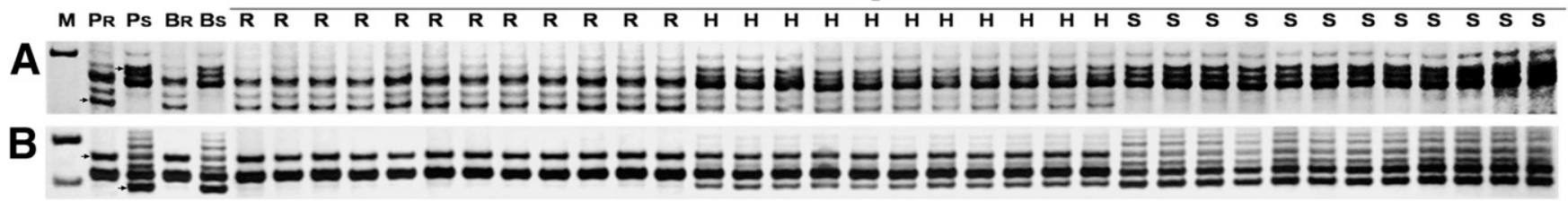

Fig. 1. A, Silver-stained polyacrylamide gels showing the simple sequence repeat (SSR) markers $X 2 A S 33$ and $\mathrm{B}, X w m c 382$ associated with the resistance locus. $P_{R}$ and $P_{S}$ denote $\mathrm{CH} 7086$ and Taichung 29, respectively; $B_{R}$ and $B_{S}$ denote the resistant and susceptible bulks, respectively. Selected homozygous resistant $(R)$, homozygous susceptible $(S)$ and heterozygous $(H) F_{2}$ plants from the Taichung $29 \times \mathrm{CH} 7086$ cross are included. M, 100-bp DNA ladder; arrows on the left side indicate the fragment linked to the resistance gene.

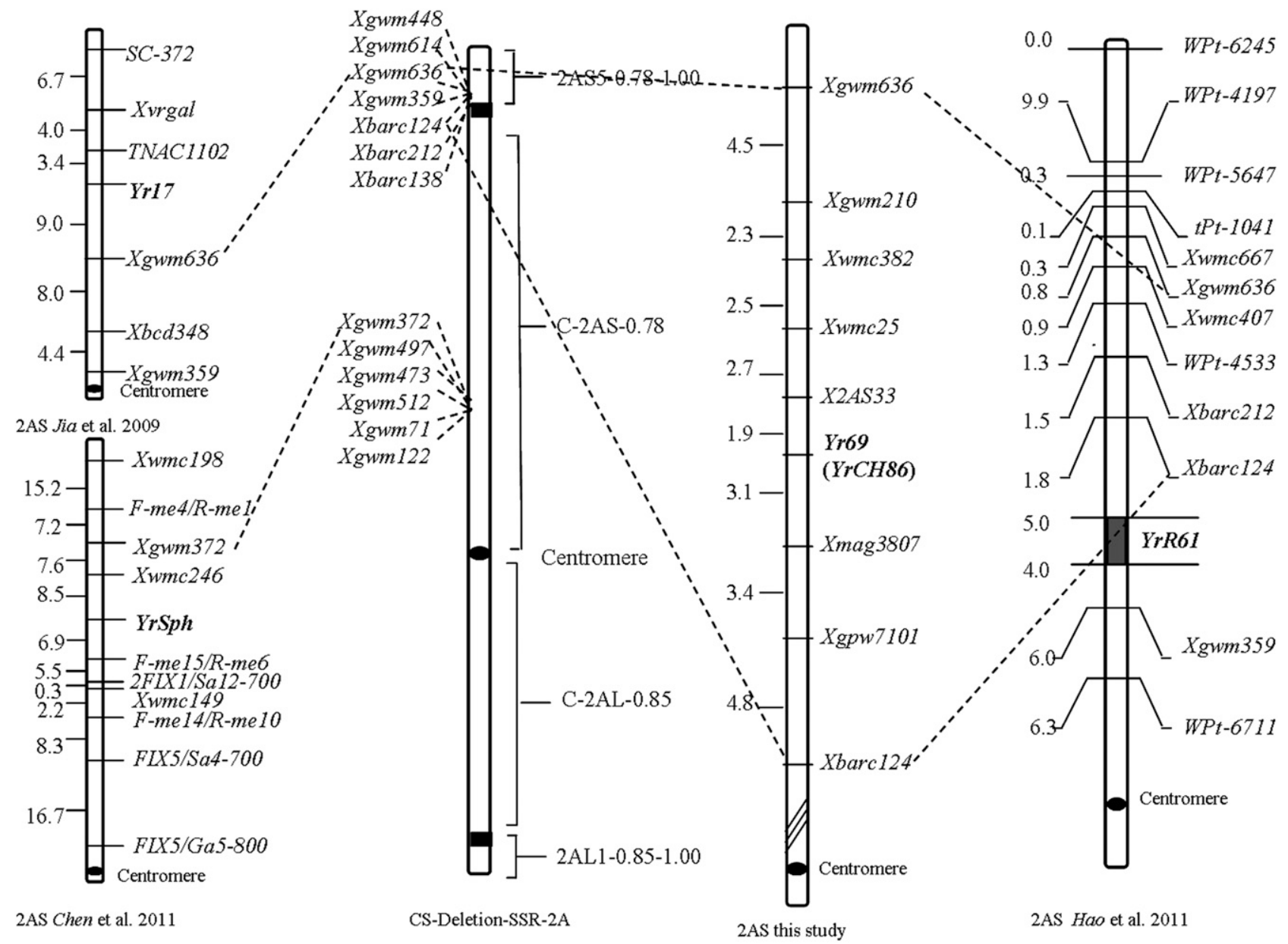

Fig. 2. The map position of Yr69 on chromosome 2AS and comparison with other Yr genes on this arm. The genetic maps of Yr17, YrSph, and YrR61 were from Jia et al. (2011), Chen et al. (2012), Hao et al. (2011), respectively. The order of the simple sequence repeat markers in the physical map for hexaploid wheat was from a USDA Graingenes database (http://wheat.pw.usda.gov/cgi-bin/cmap). 
Thinopyrum ponticum as a probe. This indicates that if a translocation was present, its size was too small to be detected through cytology. To determine the possible origin of $Y r 69$, the linked markers $X 2 A S 33$, Xgpw7101, Xmag3807, and Xbarc124 were also screened for polymorphisms among the Thinopyrum ponticum accession R431, CH7086 and its resistance donor XY7430, as well as their wheat parental lines Z 8701, JM 26, MSZ, and XY 4. The genotyping analysis revealed that no allele in $\mathrm{CH} 7086$ was found to be inherited from Thinopyrum ponticum at the four marker loci linked to the $\mathrm{YrCH} 86$ gene (data not shown). However, the stripe rust evaluation showed that, when tested at the seedling stage, $\mathrm{CH} 7086$ had the same or similarly low reactions to the nine Chinese $P$. striiformis $\mathrm{f}$. sp. tritici races as R431 and XY7430, whereas all the wheat parents were susceptible to most $P$. striiformis $\mathrm{f}$. sp. tritici races (Table 1). This suggests that a cryptic introgression from Thinopyrum ponticum appears to be present in $\mathrm{CH} 7086$ and to be associated with rust resistance.

Relationship between $\mathrm{YrCH86}$ and $\mathrm{Yr17}$. $\mathrm{YrCH} 86$ was assigned to the distal part of chromosome 2AS within a region flanked by X2AS33 (distal) and Xmag3807 (proximal) (Fig. 2). Yr17, derived from Aegilops ventricosa, was also assigned to the distal part of 2AS (Helguera et al. 2003) and is the only formally named $Y r$ gene in this region of chromosome 2A. A carrier of $\operatorname{Yr} 17$, AvS Yr17NIL, was resistant (IT 0;) to races CYR23 and CH42 and susceptible (IT 3) to races CYR29, CYR32, and CYR33, at the seedling stage (Zeng et al. 2014), whereas CH7086 was highly resistant (IT 0-0;) to all the races tested (Table 1). This indicated that $\mathrm{YrCH} 86$ differs in specificity from $\operatorname{Yr} 17$.

In order to further clarify the genetic relationship of $\mathrm{YrCH} 86$ and $\operatorname{Yr} 17,318 \mathrm{~F}_{2}$ plants from the AvS Yr17NIL $\times$ CH7086 cross were inoculated with CYR23. Four susceptible plants were identified, and the frequency of resistant and susceptible plants deviated from the 15:1 ratio expected for independent segregation of dominant alleles at two loci $\left(\chi^{2}{ }_{15: 1}=13.53, P_{\mathrm{df1}}<0.01\right)$, confirming that $\mathrm{YrCH} 86$ and $\mathrm{Yr} 17$ were neither allelic nor genetically independent. Assuming linkage, the frequency of susceptible plants in a repulsion phase cross is $p^{2} / 4$, where $p$ is the recombination value. The recombination value for $\mathrm{YrCH} 86$ and $\mathrm{Yrl} 7$ was estimated to be 0.224 . After converting the recombination value, using the formula $d=-1 / 2 \operatorname{Ln}(1-2 p)$, the map distance was determined to be $29.8 \mathrm{cM}$.

\section{Discussion}

Potential role of $\mathrm{YrCH86}$ in the improvement of stripe rust resistance. In China, some stripe rust resistance genes have been incorporated into commercial wheat cultivars, but few remain effective against the $P$. striiformis $\mathrm{f}$. sp. tritici races CYR32 and
CYR33 (Wang et al. 2010). In our search for new sources of resistance, CH7086 showed high levels of resistance to all current Chinese $P$. striiformis f. sp. tritici races in the greenhouse (Table 1) and in the field nurseries. This line also exhibits excellent resistance to powdery mildew (conferred by Pm51 [Zhan et al. 2014]), but these resistances are not associated. Markers that cosegregate with or are closely linked to $\mathrm{YrCH} 86$ can be used to accelerate the incorporation of this gene into commercial cultivars by marker-assisted selection. Therefore, there is a high likelihood that the material described in the present study is a valuable source for resistance breeding and can be utilized by breeders, especially in southwestern China.

Chromosomal location of $\mathrm{YrCH86}$ and comparison with other Yr genes on 2AS. So far, more than 60 formally designated stripe rust resistance genes have been reported (Cheng et al. 2014; http://wheat. pw.usda.gov/). It is essential that wheat pathologists and breeders continue to search for new sources of resistance because of the ongoing emergence and spread of new races virulent to currently resistant varieties. $\mathrm{CH} 7086$ is one such source. To investigate the inheritance of the stripe rust resistance in $\mathrm{CH} 7086$. we developed segregating populations. The segregation patterns showed that the resistance was controlled by a single dominant allele located on chromosome 2AS. Eight molecular markers on chromosome 2AS were linked to $\mathrm{YrCH86.} \mathrm{We} \mathrm{verified} \mathrm{the} \mathrm{chromosomal} \mathrm{locations} \mathrm{of} \mathrm{the} \mathrm{linked} \mathrm{micro-}$ satellite loci, using the Chinese Spring NT and Dt stocks and 2AS deletion lines (Fig. 3), because molecular markers are not always chromosome-specific (Plaschke et al. 1996). The presence of PCR products of the same size in $\mathrm{CH} 7086$ and in the euploid Chinese Spring and the absence of the PCR products in certain deletion lines confirmed the physical locations of the linked markers in deletion bin 2AS-5 (FL 0.78-1.00).

Previously, stripe rust resistance genes $\mathrm{Yr17}$, YrSph, and $\mathrm{YrR61}$ were located on chromosome 2AS. $\operatorname{Yr} 17$, the only formally named $\mathrm{Yr}$ gene in this region of chromosome 2A, originated from Aegilops ventricosa $\left(2 n=4 x=28, \mathrm{D}^{\mathrm{V}} \mathrm{D}^{\mathrm{V}} \mathrm{M}^{\mathrm{V}} \mathrm{M}^{\mathrm{V}}\right)$ (Helguera et al. 2003). More recently, Jia et al. (2011), through a comparative genomics analysis using EST-SSR and the syntenic region in rice, developed a genetic linkage map of the $\mathrm{Yr} 17$ locus. $\mathrm{Yr} 17$ (or the translocation breakpoint) mapped to $9.0 \mathrm{cM}$ distal to $X g w m 636$, whereas, in the present study, $\mathrm{YrCH} 86$ was $13.9 \mathrm{cM}$ proximal to $\mathrm{Xgwm636}$ (Fig. 2). This indicates that $\mathrm{YrCH} 86$ is proximal to $\mathrm{Yrl} 7$ (or the breakpoint) with an estimated genetic distance of $22.9 \mathrm{cM}$. A test of the allelism of $\mathrm{YrCH} 86$ and $\mathrm{Yr} 17$ indicated a low level of recombination and an estimated genetic distance of $29.8 \mathrm{cM}$. In addition, the resistance conferred by $\mathrm{YrCH} 86$ to the Chinese $P$. striiformis $\mathrm{f}$. sp. tritici races CYR29, CYR32, and CYR33 was also different from that of AvS Yr17NIL (Table 1).

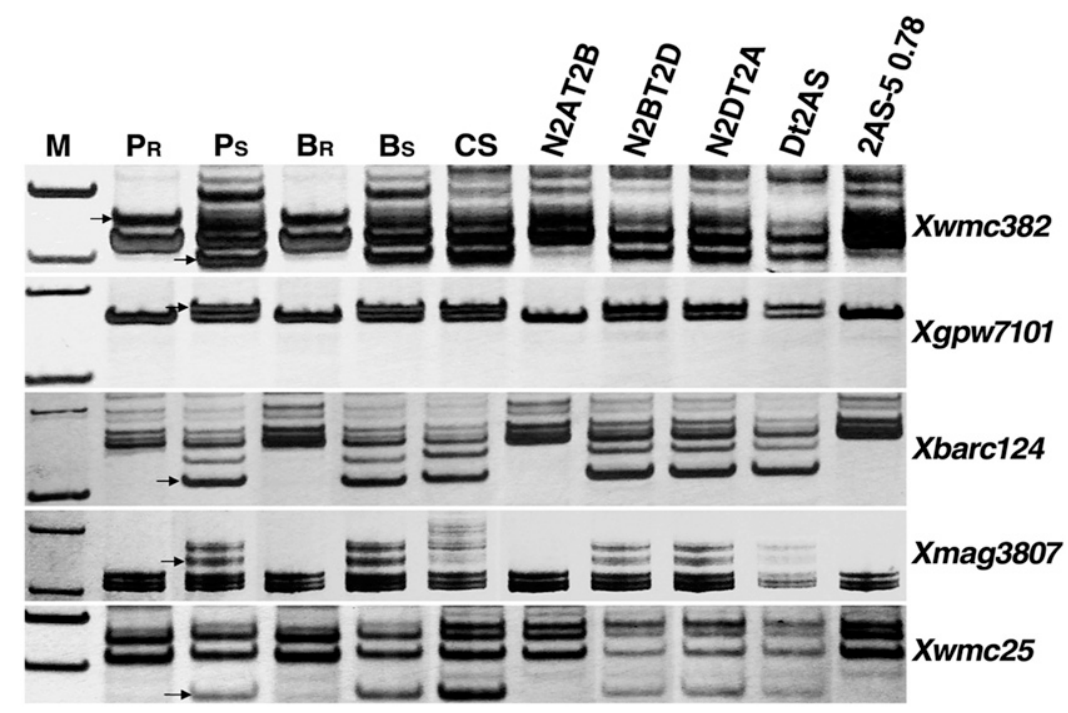

Fig. 3. Amplification patterns of the linked markers in $\mathrm{CH} 7086\left(P_{R}\right)$, Taichung (TC) $29\left(P_{S}\right)$, resistant bulk $\left(B_{R}\right)$, susceptible bulk ( $\left.B_{S}\right)$, Chinese Spring (CS), nullisomic-tetrasomic (NT) 2A, ditelosomic (Dt) 2AS stocks, and the homozygous deletion line 2AS-5 of CS. Arrows indicate the critical bands. 
The recessive $Y r S p h$ gene was located in the region between Xwmc246 and Xwmc149, approximately $13 \mathrm{cM}$ distal to Xwmc149 (Chen et al. 2012). Because Xbarc124 was situated $23 \mathrm{cM}$ distal to Xwmc149 on the consensus map (Somers et al. 2004), YrSph is predicted to be approximately $10 \mathrm{cM}$ proximal to Xbarc124. In the present study, $\mathrm{YrCH} 86$ was placed $11.3 \mathrm{cM}$ distal to Xbarc124 (Fig. 2), thus the genetic distance between $\mathrm{YrSph}$ and $\mathrm{YrCH} 86$ should be approximately $21.0 \mathrm{cM}$. YrR61, a major quantitative trait locus for adult plant resistance explaining $56.0 \%$ of the total phenotypic variation in stripe rust response in a RIL population, was also mapped to the terminal bin of chromosome 2AS, approximately $5 \mathrm{cM}$ proximal to Xbarc124 (Hao et al. 2011), whereas $\mathrm{YrCH} 86$ was placed $11.3 \mathrm{cM}$ distally of that locus (Fig. 2). Therefore, $\mathrm{YrCH} 86$ and $\mathrm{YrR61}$ seem to be different loci. Based on the combined results, it appears that $\mathrm{YrCH} 86$ is different from the other known $\mathrm{Yr}$ genes on chromosome 2AS and represents a novel $\mathrm{Yr}$ locus and, thus, was permanently designated $\mathrm{Yr} 69$.

Possible origin of the stripe rust resistance in CH7086. Genetic variation is essential for developing new plant varieties. It can be achieved by introducing genes from a related species or, sometimes, from a relatively distant species or even an unrelated species. Thinopyrum ponticum, an important perennial Triticeae species, is immune to stripe rust, and certain wheat derivatives of Thinopyrum ponticum are also highly resistant. For example, a resistance gene was recently found in the partial amphiploid XY 7430 and the substitution line $6 \mathrm{~J}^{\mathrm{s}}(6 \mathrm{~B})$, in which the $\mathrm{J}^{\mathrm{s}}$-chromosome of Thinopyrum ponticum was substituted for chromosome 6B in wheat (Hu et al. 2011). However, there is no published report of the transfer of stripe rust resistance to a wheat chromosome from this species. $\mathrm{CH} 7086$, a putative derivative of Thinopyrum ponticum, was produced by crossing and backcrossing the XY 7430 line with susceptible wheat cultivars and selecting for stripe rust resistance. However, there was no documented record of the chromosome status of the individual plants involved in each step. CH7086, R431, and XY7430 had very similar reactions to each of the nine $P$. striiformis $\mathrm{f}$. sp. tritici races, while all common wheat parents in the pedigree of the line are highly susceptible (Table 1). This indicates that the resistance in $\mathrm{CH} 7086$ is assumed to derive from Thinopyrum ponticum. Genetic segregation data clearly indicate the presence of a single dominant resistance gene in $\mathrm{CH} 7086$ (Table 2). None of the permanently named wheat genes for stripe rust resistance is derived from Thinopyrum ponticum. The resistance gene in $\mathrm{CH} 7086$ seems to involve a novel locus, as its origin and chromosomal location indicate. However, GISH and Giemsa C-banding analyses of $\mathrm{CH} 7086$ have produced no cytological evidence for an alien translocation (Zhan et al. 2014) (data not shown), suggesting that the translocated Thinopyrum ponticum chromosomal fragments may be too small to be detected by GISH. Such cryptic alien transfers have been reported in other studies (He et al. 2009; Huang et al. 2014; Kuraparthy et al. 2007; Lu et al. 2015). To determine the origin of the gene, four linked markers around $\operatorname{Yr} 69$ were screened, and a specific marker inherited from Thinopyrum ponticum was not found in CH7086; it is possible that we have not tested a sufficient number of markers. More available markers that could have been transferred can be used to provide information on this introgression. The gene Yr69, based on its widespread effectiveness and unique chromosome location, must be either present in an intercalary cryptic translocation from Thinopyrum ponticum or a wheat gene derived from an unknown source. More detailed studies are needed to better elucidate the source of $\operatorname{Yr} 69$.

In conclusion, we found a new stripe rust resistance gene, formally named $\mathrm{Yr} 69$, which was putatively derived from Thinopyrum ponticum. It was mapped distally on chromosome $2 \mathrm{AS}$ and flanked by the closely linked markers X2AS33 and Xmag3807. These markers, especially if used jointly, are adequate for use in marker-assisted selection aimed at combining multiple resistance genes into a variety to achieve more durable resistance.

\section{Acknowledgments}

We thank R. McIntosh and P. Zhang (University of Sydney, Australia) for critical reviews of this manuscript, and the National Natural Science Foundation of China (grant mumber 31171839, 31101199), Shanxi Financial Support for Agriculture Project (2014ZYFZ-03, 2015ZYZX-03), Shanxi Program for Sci-Tech
Development (Agriculture) (20150311001-1), and Shanxi Natural Science Foundation for Young Scientists (2015021145) for funding support.

\section{Literature Cited}

Chen, S. S., Chen, G. Y., Chen, H., Wei, Y. M., Li, W., Liu, Y. X., Liu, D. C., Lan, X. J., and Zheng, Y. L. 2012. Mapping stripe rust resistance gene YrSph derived from Triticum sphaerococcum Perc. with SSR, SRAP, and TRAP markers. Euphytica 185:19-26.

Chen, W. Q., Wu, L. R., Liu, T. G., Xu, S. C., Jin, S. L., Peng, Y. L., and Wang, B. T. 2009. Race dynamics, diversity, and virulence evolution in Puccinia stiiformis $\mathrm{f}$. sp. tritici, the causal agent of wheat stripe rust in China from 2003 to 2007. Plant Dis. 93:1093-1101.

Chen, X. M. 2005. Epidemiology and control of stripe rust [Puccinia striiformis f. sp. tritici] on wheat. Can. J. Plant Pathol. 27:314-337.

Cheng, P., Xu, L. S., Wang, M. N., See, D. R., and Chen, X. M. 2014. Molecular mapping of genes $\operatorname{Yr} 64$ and $Y r 65$ for stripe rust resistance in hexaploid derivatives of durum wheat accessions PI 331260 and PI 480016. Theor. Appl. Genet. 127:2267-2277.

Eriksen, L., Afshari, F., Christiansen, M. J., McIntosh, R. A., Jahoor, A., and Wellings, C. R. 2004. Yr32 for resistance to stripe rust present in the wheat cultivar Carstens V. Theor. Appl. Genet. 108:567-576.

Fu, D. L., Uauy, C., Distelfeld, A., Blechl, A., Epstein, L., Chen, X. M., Sela, H., Fahima, T., and Dubcovsky, J. 2009. A kinase-START gene confers temperature-dependent resistance to wheat stripe rust. Science 323:1357-1360.

Hao, Y. F., Chen, Z. B., Wang, Y. Y., Bland, D., Buck, J., Brown-Guedira, G., and Johnson, J. 2011. Characterization of a major QTL for adult plant resistance to stripe rust in US soft red winter wheat. Theor. Appl. Genet. 123:1401-1411.

He, R. L., Chang, Z. J., Yang, Z. J., Yuan, Z. Y., Zhan, H. X., Zhang, X. J., and Liu, J. X. 2009. Inheritance and mapping of a powdery mildew resistance gene $P m 43$ introgressed from Thinopyrum intermedium into wheat. Theor. Appl. Genet. 118:1173-1180.

Helguera, M., Khan, I. A., Kolmer, J., Lijavetzky, D., Li, Z. Q., and Dubcovsky, J. 2003. PCR assays for the Lr37-Yr17-Sr38 cluster of rust resistance genes and their use to develop isogenic hard red spring wheat lines. Crop Sci. 43: $1839-1847$.

Hu, L. J., Li, G. R., Zeng, Z. X., Chang, Z. J., Liu, C., and Yang, Z. J. 2011. Molecular characterization of a wheat-Thinopyrum ponticum partial amphiploid and its derived substitution line for resistance to stripe rust. J. Appl. Genet. 52:279-285.

Huang, Q., Li, X., Chen, W. Q., Xiang, Z. P., Zhong, S. F., Chang, Z. J., Zhang, M. Zhang, H. Y., Tan, F. Q., Ren, Z. L., and Luo, P. G. 2014. Genetic mapping of a putative Thinopyrum intermedium-derived stripe rust resistance gene on wheat chromosome 1B. Theor. Appl. Genet. 127:843-853.

International Wheat Genome Sequencing Consortium (IWGSC). 2014. A chromosome-based draft sequence of the hexaploid bread wheat (Triticum aestivum) genome. Science 345:1251788.

Jewell, E., Robinson, A., Savage, D., Erwin, T., Love, C. G., Lim, G. A. C., Li, X., Batley, J., Spangenberg, G. C., and Edwards, D. 2006. SSR primer and SSR taxonomy tree: Biome SSR discovery. Nucleic Acids Res. 34:W656-W659.

Jia, J. Q., Li, G. R., Liu, C., Lei, M. P., and Yang, Z. J. 2011. Characterization of wheat yellow rust resistance gene $\mathrm{Yr} 17$ using EST-SSR and rice syntenic region. Cereal Res. Commun. 39:88-99.

Kang, Z. S., Zhao, J., Han, D. J., Zhang, H. C., Wang, X. J., Wang, C. F., Han, Q. M., Guo, J., and Huang, L. L. 2010. Status of wheat rust research and control in China. Pages 1-21 in: Borlaug Global Rust Initiative, Technical Workshop, 3031 May 2010, St. Petersburg, Russia.

Kuraparthy, V., Chhuneja, P., Dhaliwal, H. S., Kaur, S., Bowden, R. L., and Gill, B. S. 2007. Characterization and mapping of cryptic alien introgression from Aegilops geniculata with leaf rust and stripe rust resistance genes Lr57 and Yr40 in wheat. Theor. Appl. Genet. 114:1379-1389.

Li, Z. F., Zheng, T. C., He, Z. H., Li, G. Q., Xu, S. C., Li, X. P., Yang, G. Y., Singh, R. P., and Xia, X. C. 2006. Molecular tagging of stripe rust resistance gene YrZH84 in Chinese wheat line Zhou 8425B. Theor. Appl. Genet. 112:1098-1103.

Li, Z. S., Rong, S., Chen, S. Y., Zhong, G. C., and Mu, S. M. 1985:Pages 72-75 in: Wheat wide hybridization. Chinese Scientific Press, Beijing.

Li, Z. S., and Zeng, S. M. 2002:Pages 286-288 in: Wheat rust in China. China Agricultural Press, Beijing. (In Chinese)

Liu, J., Chang, Z. J., Zhang, X. J., Yan, Z. J., Li, X., Jia, J. Q., Zhan, H. X., Guo, H. J., and Wang, J. M. 2013. Putative Thinopyrum intermedium-derived stripe rust resistance gene $\mathrm{Yr} 50$ maps on wheat chromosome arm 4BL. Theor. Appl. Genet. 126:265-274.

Liu, T. G., Peng, Y. L., Chen, W. Q., and Zhang, Z. Y. 2010. First detection of virulence in Puccinia striiformis f. sp. tritici in China to resistance genes Yr24 (=Yr26) present in wheat cultivar Chuanmai 42. Plant Dis. 94:1163.

Lu, Y. Q., Wu, X. Y., Yao, M. M., Zhang, J. P., Liu, W. H., Yang, X. M., Li, X. Q., Du, J., Gao, A. N., and Li, L. H. 2015. Genetic mapping of a putative Agropyron cristatum-derived powdery mildew resistance gene by a combination of bulked segregant analysis and single nucleotide polymorphism array. Mol. Breeding 35:96.

Marone, D., Laidò, G., Gadaleta, A., Colasuonno, P., Ficco, D. B. M., Giancaspro, A., Giove, S., Panio, G., Russo, M. A., Vita, P. D., Cattivelli, L., Papa, R., Blanco, A., and Mastrangelo, A. M. 2012. A high density consensus map of A and B wheat genomes. Theor. Appl. Genet. 125:1619-1638. 
Murphy, L. R., Santra, D., Kidwell, K., Yan, G. P., Chen, X. M., and Campbell, K. G. 2009. Linkage maps of wheat stripe rust resistance genes $\mathrm{Yr} 5$ and $\mathrm{Yr} 15$ for use in marker-assisted selection. Crop Sci. 49:1786-1790.

Plaschke, J., Börner, A., Wendehake, K., Ganal, M. W., and Röder, M. S. 1996. The use of wheat aneuploids for the chromosomal assignment of microsatellite loci. Euphytica 89:33-40.

Singh, R., Datta, D., Priyamvada. Singh, S., and Tiwari, R. 2009. A diagnostic PCR based assay for stripe rust resistance gene YrlO in wheat. Acta Phytopathol. Entomol. Hung. 44:11-18.

Somers, D. J., Isaac, P., and Edwards, K. 2004. A high density microsatellite consensus map for bread wheat (Triticum aestivum L.). Theor. Appl. Genet. 109:1105-1114.

Sourdille, P., Singh, S., Cadalen, T., Brown-Guedira, G. L., Gay, G., Qi, L., Gill, B. S., Dufour, P., Murigneux, A., and Bernard, M. 2004. Microsatellite-based deletion bin system for the establishment of genetic physical map relationships in wheat (Triticum aestivum L.). Funct. Integr. Genomics 4:12-25.

Stein, N., Herren, G., and Keller, B. 2001. A new DNA extraction method for highthroughout marker analysis in a large-genome species such as Triticum aestivum. Plant Breed. 120:354-356.

van Ooijen, J. W. 2006. JoinMap 4.0: Software for the calculation of genetic linkage maps in experimental populations. Kyazma BV, Wageningen, The Netherland.
Wan, A. M., Chen, X. M., and He, Z. H. 2007. Wheat stripe rust in China. Aust. J. Agric. Res. 58:605-619.

Wang, B. T., Hu, X. P., Li, Q., Hao, B. J., Zhang, B., Li, G. B., and Kang, Z. S. 2010 Development of race specific SCAR markers for detection of Chinese races CYR32 and CYR33 of Puccinia striiformis f. sp. tritici. Plant Dis. 94:221-228.

Wang, C. M., Zhang, Y. P., Han, D. J., Kang, Z. S., Li, G. P., Cao, A. Z., and Chen, P. D. 2008. SSR and STS markers for wheat stripe rust resistance gene Yr26. Euphytica 159:359-366

Xue, S. L., Zhang, Z. Z., Lin, F., Kong, Z. X., Cao, Y., Li, C. J., Yi, H. Y., Mei, M. F., Zhu, H. L., Wu, J. Z., Xu, H. B., Zhao, D. M., Tian, D. G., Zhang, C. Q., and Ma, Z. Q. 2008. A high-density intervarietal map of the wheat genome enriched with markers derived from expressed sequence tags. Theor. Appl. Genet. 117:181-189.

Zeng, Q. D., Han, D. J., Wang, Q. L., Yuan, F. P., Wu, J. H., Zhang, L., Wang, X. J., Huang, L. L., Chen, X. M., and Kang, Z. S. 2014. Stripe rust resistance and genes in Chinese wheat cultivars and breeding lines. Euphytica 196 271-284.

Zhan, H. X., Li, G. R., Zhang, X. J., Li, X., Guo, H. J., Gong, W. P., Jia, J. Q., Qiao, L. Y., Ren, Y. K., Yang, Z. J., and Chang, Z. J. 2014. Chromosomal location and comparative genomics analysis of powdery mildew resistance gene Pm51 in a putative wheat-Thinopyrum ponticum introgression line. PLoS One 9:e113455. 